This is an Accepted Manuscript of an article published by Taylor \& Francis in Disability and Rehabilitation on January 2019, available online: http://wwww.tandfonline.com/

10.1080/09638288.2018.1532462.

\title{
What really matters in pediatric chronic pain rehabilitation? Results of a multi-stakeholder nominal group technique study.
}

\begin{abstract}
Purpose: To prioritize outcome domains sensitive to the needs of the various stakeholders involved in rehabilitation programs designed for youth with pain-related disability using the International Classification of Function Child and Youth version.
\end{abstract}

Materials and Methods: A 5-step nominal group technique was conducted with 13 stakeholders, including 2 youth with pain-related disability, 2 parents, 5 clinicians, 2 teachers, and 2 healthcare managers. Once identified by content thematic analysis and International Classification of Function linking, 15 outcome domains were ranked. Priority rank scores were then weighted.

Results: Six outcome domains were prioritized: 1) activities of daily living, 2) participation in meaningful activities, 3) social roles and relationships, 4) mood and affect, 5) school engagement, and 6) self-efficacy. Discrepancies in ranking existed; parents and youth attributed importance to pain, sleep, and program satisfaction whereas clinicians and mangers underscored pain-related fear and family functioning. When compared, prioritized domain associated with three PedIMMPACT recommendations, and aligned with the activity and participation components of the International Classification of Function for Child and Youth.

Conclusion: These findings emphasize the importance of integrating various perspectives, including those of youth with pain-related disability and other important stakeholders and adopting a broader conceptualization of disability and function when selecting key rehabilitation evaluation outcome for this population.

Key Words: Pediatric pain-related disability; rehabilitation programs; outcomes; specialized pain treatment; program evaluation 
This is an Accepted Manuscript of an article published by Taylor \& Francis in Disability and Rehabilitation on January 2019, available online: http://wwww.tandfonline.com/

$$
10.1080 / 09638288.2018 .1532462 .
$$

\section{Introduction}

Youth living with chronic pain experience significant functional impairments, activity limitations, participation restrictions, social isolation, decreased quality of life, detrimental effects on family functioning and long-term mental health problems, resulting in a painrelated disability $[1,2,3,4]$. As compared to the extensive research available on interdisciplinary adult pain interventions, program evaluation evidence for pediatric interdisciplinary pain rehabilitation (IPR) programs is scarce [5]. The information about program impact is however central in guiding further implementation of appropriate rehabilitation programs for this younger population.

The stated goal of most pediatric IPR programs is to improve the child's functioning, despite pain [5]. However, few IPR programs have named the conceptual framework underpinning their program or the theoretical basis for understanding disability and functioning, and the impact on these youth. The International Classification of Function for Children and Youth (ICF-CY) is a widely accepted biopsychosocial framework for describing and categorizing functioning and disability in children and youth worldwide [6]. Its focus is on impact or effect and not on cause [7], describing functioning and the health condition from the perspectives of body functions and structures, activities and participation. The umbrella terms 'functioning' and 'disability' are considered to be the result of the dynamic interaction between the health condition and environmental factors with special consideration given to aspects of child and adolescent development [6]. Currently utilized by service providers, researchers and policy-makers in a range of sectors for multiple purposes, the ICF-CY framework offers a shared language known to fosters interdisciplinary and multisectorial collaboration $[8,9]$.

Collaboration amongst diverse stakeholders (e.g. school personnel, sports coaches, choir and band conductors, church group leaders) across multiple sectors (e.g. education, 
This is an Accepted Manuscript of an article published by Taylor \& Francis in Disability and Rehabilitation on January 2019, available online: http://wwww.tandfonline.com/

$10.1080 / 09638288.2018 .1532462$.

health, recreation and leisure, religion) is required in IPR programs [10]. This diversity can create challenges in establishing common outcomes upon which rehabilitation program success or failure is judged [11]. Stakeholder values, beliefs, and interests strongly impact the perspectives of program worth $[11,12,13]$. Moreover, when stakeholders do not completely agree on a shared purpose, the next steps of the collaborative process are at risk, creating conflict about the key indicators, and their interpretation [11]. Engagement of stakeholders at all organisational levels and across collaborative networks is key in achieving agreement on the important outcomes, without overlooking important impacts [14].

Attempts have been made to identify standardized outcome domains in pediatric pain in an effort to streamline study design, protocols, and assist clinicians in decision-making $[5,15]$. The PedIMMPACT recommendations were foundational in identifying eight core outcome domains and suggesting associated evidence-based measures for pediatric acute and chronic/recurrent pain clinical trials [15]. However, only four of the eight recommended outcome domains are routinely used in IPR program effectiveness studies. These include pain intensity, physical (i.e. disability), emotional (i.e. depression \& anxiety), and school functioning [5]. Although, the PedIMMPACT did not recommend measurement of each domain in every study, it did call for those included to be justified to ensure useful interpretation of the published conclusions by researchers and clinicians [5]. With the recent promotion of patient-oriented outcomes, useful interpretation extends beyond statistical difference, to clinical relevance (i.e. the lowest level of change considered relevant by the patients in outcomes that are important to them) [16]. The PedIMMPACT outcome domain selection process did not formally integrate youth with pain-related disability or their parents, nor have they been included in previous effectiveness IPR evaluations. Consequently, little is known about what is clinically relevant or important to this patient population. 
This is an Accepted Manuscript of an article published by Taylor \& Francis in Disability and Rehabilitation on January 2019, available online: http://wwww.tandfonline.com/

$10.1080 / 09638288.2018 .1532462$.

Input from other important stakeholder groups is also missing from the PedIMMPACT. School is central to the lives of adolescents [17]. Although school functioning has been acknowledged as a critical outcome, school attendance is the recommended and most frequently used indicator of this domain [5,15]. Evidence suggests that adolescents with chronic pain experience much broader school impairments (e.g. poor self-perception of academic competence, school avoidance, impaired ability to cope with classroom demands, peer-group participation), strongly suggesting that a more comprehensive picture of school functioning is required $[17,18,19]$. Contextual knowledge and pedagogical expertise of teachers and school personnel may be critical in advancing the conceptualisation of this domain.

Decision-makers from various levels of healthcare organizations are another group whose perspective, expertise and influence may be useful, yet overlooked to date. The involvement of organizational leaders and managers in research from the beginning enhances the understanding of the complexities of the organizational context and needs and improves the relevance of the research generated to solving real-world problems [20,21,22]. In particular, middle managers, strategically located between senior leaders and frontline employees (e.g. providers, booking clerks), have received attention in the implementation of innovation and research due to their ability to bridge associated informational gaps, align resources and incentives, transcend professional barriers, and identify priorities, thus increasing the projects feasibility, outcomes, and sustainability [21,22].

With the evolution of theories about pediatric chronic pain and disability [15], the observable shift toward person- and family-centred care, the recognition of the need for patient-oriented outcomes and the call for greater stakeholder involvement by the rehabilitation community $[24,25]$, it seems timely to revisit the PedIMMPACT recommendations. Innovative approaches are needed to reconcile the outcomes valued by 
This is an Accepted Manuscript of an article published by Taylor \& Francis in Disability and Rehabilitation on January 2019, available online: http://wwww.tandfonline.com/

$$
10.1080 / 09638288.2018 .1532462 .
$$

different stakeholder groups and to design pediatric IPR program effectiveness evaluations. The purpose of this study is to generate and prioritize outcome domains, sensitive to the needs of various stakeholders involved in IPR programs, including youth with pain-related disability, their parents, clinicians, teachers, and managers. This study also aimed to provide valuable information about the feasibility of using a formalized consensus-building process in selecting pain rehabilitation program outcomes with a very diverse group of stakeholders. Building on multi-stakeholder perspectives, the outcome domains selected will be used in the development of a comprehensive effect analysis of a pediatric interdisciplinary pain rehabilitation program.

\section{Materials and Methods}

\section{Study Design}

This context-specific study used a nominal group technique, a common consensus method used to democratically make group decisions [26,27]. Descriptive statistics and a qualitative content thematic analysis [28,29] were used to make sense of the data. This study was the first step in a larger participatory research project aimed at evaluating the effectiveness and efficiency of a new intensive pain rehabilitation program, for which ethical approval was obtained from the appropriate institutional research ethics boards.

\section{Participants}

A purposeful sample of stakeholders involved in services aimed at youth with chronic pain at Alberta Children's Hospital were recruited via an email invitation; individuals were identified by the hospital leadership and school administrative teams, and the Complex Pain Clinic program. To be included, hospital ( $\mathrm{n}=5$ clinicians; $\mathrm{n}=2$ middle managers), and school personnel $(n=2)$ were required to be actively involved in providing interdisciplinary pain 
This is an Accepted Manuscript of an article published by Taylor \& Francis in Disability and Rehabilitation on January 2019, available online: http://wwww.tandfonline.com/

$10.1080 / 09638288.2018 .1532462$.

rehabilitation intervention to youth with pain-related disability and their families for at least 2 years and be committed to the meeting schedule and activities. Youth needed to be 15-21 years of age and have chronic pain, past involvement with the pediatric Complex Pain Clinic for at least 1 year and be discharged from the clinic at the time of recruitment $(n=2)$. Parents had to have a child or adolescent meeting the above-mentioned criteria $(n=2)$. Once interest was established, the consent process was completed. No standard method to calculate sample size has been reported in the literature when using consensus methods [30], however 5 to 15 participants have been suggested as a sufficient number to ensure group judgment reliability, while limiting group coordination issues $[30,31,32]$. Furthermore, heterogeneity of the group is recommended, reflecting a full range of stakeholders' perspectives, who have an interest in the study results, and thus increasing the credibility and the acceptance of the indicators selected [30]. As inviting more participants increases of group judgement reliability and the variety of expertise and perspective, we chose to approximate the higher limit of participants suggested [30].

In order to describe the characteristics and assess participants' representativeness, a demographic questionnaire was distributed, which examined participants' age, sex, and years of experience with pediatric chronic pain. As per Table 1, the recruited participants were predominantly female (77\%) and were over 40 years of age $(54 \%)$. The majority of clinician, manager and teacher participants had at least 6 years of experience with youth with chronic pain $(69 \%)$. When compared to samples described in the literature, our clinician sample was deemed representative, based on age, sex and years of experience with pain [5,33,34].

[Insert Table 1 about here]

Parents and youth participants were from the same family and had at least 5 years of experience managing a pediatric chronic pain condition. Although the invitation to participate in this study was extended to all 16 eligible youth and families and repeated attempts (up to 
This is an Accepted Manuscript of an article published by Taylor \& Francis in Disability and Rehabilitation on January 2019, available online: http://wwww.tandfonline.com/

10.1080/09638288.2018.1532462.

3) to contact those who did not respond, only two youth-parent dyads [13\%] agreed to volunteer. Of the $88 \%$ of families who were considered non-responders in the overall sample, 6 families did not respond [37\%], while the other 8 stated they were unable to participate [50\%]due a combination of factors; these included a lack of time $(n=8)$, school $(n=4)$ and extracurricular activities commitments $(n=2)$, distance from hospital and transportation issues $(n=6)$.

\section{Procedures}

The nominal group technique (NGT): Participants were asked to respond individually to a question, aimed at generating ideas, which was then followed by judgments pooling, consensus achievement, and a voting procedure [26]. The NGT methodology is designed to avoid an individual's viewpoint dominating the discussion [32]. It was chosen for this study, as it has previously demonstrated effectiveness in engaging youth in the evaluation processes [31], and in achieving consensus on outcome domains with varied stakeholder groups $[35,36,37]$.

The NGT question was adapted from a previous study [37]. The question was piloted with all participants during the introductory phase of the study to ensure that it was: 1) broad enough to capture a range of outcomes; 2) relevant and meaningful to all participants; and 3) specific enough to stimulate discussion regarding outcomes relevant to pediatric pain-related disability interventions [35]. The final question presented to participants was "What are the effects that you consider most important to measure when evaluating the effects of an intervention for yourself/ your child/ your patient/ your student with chronic pain?”

Table 2 illustrates the NGT steps, the procedures completed at each step, and the coinciding data analysis processes. The NGT process was completed over the course of 4 months (October 2016-January 2017). The 5-step process employed in this study was 
This is an Accepted Manuscript of an article published by Taylor \& Francis in Disability and Rehabilitation on January 2019, available online: http://wwww.tandfonline.com/

10.1080/09638288.2018.1532462.

influenced by the method described by Fink and colleagues [26], and adapted to the rehabilitation context, based on Camden and colleagues [20] recommendations for fostering greater stakeholder engagement and support, and for developing a sustainable, satisfying, mutually-beneficial partnership amongst the varied groups of stakeholders.

[Insert Table 2 about here]

\section{Analysis}

As the NGT generated both quantitative and qualitative data, the analysis processes used reflected the different types of data collected.

\section{Content analysis}

A three-phase content thematic analysis framework guided the analysis of the responses from the NGT questions, and included: 1) condensing the data, 2) displaying the data, and 3) drawing and verifying conclusions [29]. As per the analysis guidelines, following the reading and re-reading of the questionnaire responses, data segments were coded (i.e. a word or short phrase was assigned to summarize the meaning of the segment) in an Excel@ spread sheet. Two members of the research team organized these codes into categories or themes; any disagreements were discussed until consensus was achieved. Descriptive statistics (i.e. the total number and frequencies for each theme) were calculated.

\section{International Classification of Function for Children and Youth (ICF-CY) Linking}

To ensure the broadness of the outcome domain themes generated and to create a focus on the impact or effect of the IPR programs on the functioning of youth with painrelated disability, the ICF-CY conceptual framework [6] was used to categorise the final list of outcome domain themes. Content analysis themes from Step 2 (i.e. Idea Generations) and those arising from the group discussions in Step 3 (i.e. Idea Recording) and Step 4 (i.e. Idea Clarification) were associated to the ICF-CY using the linking process described by Cieza and colleagues [28], where the themes were coupled with the ICF-CY categories that were 
This is an Accepted Manuscript of an article published by Taylor \& Francis in Disability and Rehabilitation on January 2019, available online: http://wwww.tandfonline.com/

10.1080/09638288.2018.1532462.

deemed most representative. One author performed the coding, with peer debriefing provided by a researcher with significant knowledge about ICF-CY framework, its components and categories. A thematic map was created demonstrating the associations between the content themes and the ICF-CY categories, as well as the relationship of those content themes that did not directly relate to the aforementioned framework.

\section{NGT ranking}

Participants' rankings of the outcome domains were summed. A priority score for domain selection was calculated by adding the importance scores (as per the 6-point Likert scale) given by every participant for each outcome domain listed. For identical rank scores, a domain receiving more stakeholder group votes was listed higher [32]. In order to adjust for varying numbers of representatives in each stakeholder group, the priority scores were weighted to achieve equal representation within each group (i.e. $20 \%$ per group); the clinician propriety score was therefore multiplied by 0.44 , that of the manager and teacher scores was magnified 2.22 times, and parents and youth scores grew by 1.11 [40].

\section{Results:}

All participants responded to the electronically distributed NGT question "What are the effects that you consider most important to measure when evaluating the effects of an intervention for yourself/ your child/ your patient/ your student with chronic pain?" and submitted their ideas. Table 3 highlights the 11 outcome domains that emerged in this second step of the NGT process (i.e. Idea Generation), along with the absolute and relative frequencies with which they were identified, and by which stakeholders.

[Insert Table 3 about here]

Four additional themes emerged from the third and fourth steps (i.e. Idea Recording and Idea Clarification) of the NGT procedure, during the group meeting discussions; this 
This is an Accepted Manuscript of an article published by Taylor \& Francis in Disability and Rehabilitation on January 2019, available online: http://wwww.tandfonline.com/

$10.1080 / 09638288.2018 .1532462$.

raised the total to 15 outcome domains. The 15 outcome domains related to the Body Functions and Structures (33\%), Activity (13\%) and Participation (20\%) components of the ICF-CY. Only 6\% linked to the Personal and Environmental factors of the framework. Table 4 presents the coding scheme and results of ICF-linking process for theses 15 themes.

\section{[Insert Table 4 about here]}

Based on these electronic responses, the most common outcome domain was Activities of Daily Living, identified by all participants [100\%] in all stakeholder groups. It was defined as routine activities that people are required to perform during the course of a normal day depending on age and developmental expectations. Included codes related to activities and tasks associated with self-care (e.g. dressing, coiffing, preparing lunches) and daily routines (e.g preparing for bed). This participant provided these descriptors:

"Independence in activities of daily living would initially be the ability to get herself out of bed, brushing her teeth, using her own alarm clock to get herself up, getting herself dressed, ready on time so she could attend school" [Parent $1]$.

It was also was linked to ambulation (e.g. walking, climbing stairs) and broader community mobility (e.g. transferring in and out of vehicles, using public transit, learning to drive), as described this individual:

"Getting out of the house required me, 'cause he could not walk more than a few feet from his wheelchair. We noticed a big step when we went from driving him to school to having him walk down and take the bus. Sounds trivial but it was huge." [Parent 2]. Self-efficacy, the second most frequently identified outcome domain was defined as one's belief and confidence in their ability to succeed in specific situations. Integrated codes were associated with the ability to self-manage, the confidence to problem-solve in varying 
This is an Accepted Manuscript of an article published by Taylor \& Francis in Disability and Rehabilitation on January 2019, available online: http://wwww.tandfonline.com/

$$
10.1080 / 09638288.2018 .1532462 .
$$

contexts, as well as youth and parents' abilities self-advocate in different settings (e.g. hospital, school, community). The following participants written response provides an example:

"Teens ability to self-manage their pain flares and get back to activities/life better than, faster than, without assistance or as much disruption to their routine as prior to the intervention" [Clinician 1].

The third most popular domain, Quality of Life, encompassed statements about one's feeling about their life, their short-term goals and vision for the future, as stated by this stakeholder:

"With quality of life, I can see a shift in how the kids look at the future, as far as their goals, what I'm gonna do this summer. I'm gonna go on a camping trip, I see myself becoming a doctor, going to university, and this is how I am going to get there" [Clinician 2].

Freedom to do what one wants to do when they want to do it was the definition adopted for Quality of Life domain. Throughout the clarification phases (i.e. Step 4), the complexity of this composite outcome domain theme became evident to the group as this domain could encompass several of the other domain themes such as activities of daily living, mood and affect, sleep, participation in meaningful activities, and social engagement, as expressed by this participant's comment:

"Quality of life encompassed all these things. How it is being achieved falls under all these other pieces, such as more sleep, more functioning, more participation" [Parent 1].

Due to the recognized difficulty in capturing subtle changes within a domain theme that includes so many different subdomains, participants chose to keep the subdomains separate instead of grouping all these domains under the Quality of Life. 
This is an Accepted Manuscript of an article published by Taylor \& Francis in Disability and Rehabilitation on January 2019, available online: http://wwww.tandfonline.com/

$$
10.1080 / 09638288.2018 .1532462 .
$$

The Mood and Affect outcome domain incorporated codes related to depression, as well as changes in energy and posture. This participant response described it like this:

"I have witnessed in many of the patients a change in their carriage, posture, and energy; a definite lightness in their presentation and overall a brighter demeanour. Obviously, this is a more intangible quality, but it's apparent to the staff who work with them" [Clinician 1].

This theme was defined as a state of mind or feeling at a particular time, that may be demonstrated by posture and behaviour. Participants recognized this domain as being strongly linked to the Sleep outcome domain, as explained by this participant:

"I think there is a [relationship] with sleep. More sleep gives you a better demeanour you know" [Parent 2]

More specifically, the sleep domain included codes related not only to the quantity or quality of sleep, but its relationship to daily performance expectations and one's the ability to get to and stay asleep.

The Social Roles and Relationships domain, defined by participants as the expectations, responsibilities, and behaviours adopted in certain situations, which naturally changes with age and development, comprised codes related to relationships and interactions with peers, siblings and other family members, household roles. As this participant reported:

"As he began walking longer distances, he began walking around the park. Then he would come home, notice the dogs were getting anxious and would take them out into the park with him. It was a huge help" [Parent 2].

School Engagement referred to a disposition, willingness, and desire to participate and be successful in meaningful learning processes in the classroom and school related activities. This domain involved not only codes associated with school attendance, but also school 
This is an Accepted Manuscript of an article published by Taylor \& Francis in Disability and Rehabilitation on January 2019, available online: http://wwww.tandfonline.com/

$$
\text { 10.1080/09638288.2018.1532462. }
$$

performance (e.g. grades), course load, involvement in school activities and planning for and following high-school graduation. This participant explained it like this:

"Engagement in education can be demonstrated not only by changes in school attendance, but also with an increase in number of courses completed during a school year, improvements in marks, the articulation of a post-graduation plan, participation in school-related/extra-curricular activities of interest, taking on leadership roles. It's about seeing themselves as students again" [Teacher 1 and 2].

Another participant worded it this way:

"To me there is definitely a difference between showing up at school and just making it through the day, actually being involved, working on projects, having fun with friends at school, being involved in clubs and things like that. Actually, getting something out of the school day, instead of just trying to get through the day and going home" [Youth 1].

Family Functioning adopted the definition of the capacity of the family unit to meet the needs of its members. Codes incorporated related to family stress, family members' focus on the pain, the impact of pain on family members (i.e. siblings, parents, grandparents), changes in parental roles, parental acceptance of the condition, and the effects on parents' employment and family finances. This participant scripted this way:

"Families report they are functioning despite pain, when pain is not at the forefront, and they are confident in how they effectively support their child in pain" [Clinician 3].

This participant explained it as follows:

"Another family functioning thing is the expenses associated with the condition. For example, [my child] was in a wheel chair, so we had to buy a van. That's expensive! It may seem silly, but it adds up on the things that impact the family" [Parent 2]. 
This is an Accepted Manuscript of an article published by Taylor \& Francis in Disability and Rehabilitation on January 2019, available online: http://wwww.tandfonline.com/

$$
\text { 10.1080/09638288.2018.1532462. }
$$

Pain denoted intensity, frequency, type and quality of the pain experience, as highlighted by this participant's quote:

"The character of pain to me is the change in the obsession about pain; with pain being the biggest thing in life, the only focus, to being able to focus on other things" [Parent 1].

Participants also spoke about how pain becomes less part of the youth's identity, as explained by this individual:

"I notice how the program participants initially identify or label themselves, like I have pain, I am a pain patient, whereas in follow-up sessions, some of them will instead identify or label the activities they are doing, or I'm a grade X student, I'm training for a certain race, so its changes in how they identify themselves" [Clinician 2]

Involvement in activities that were important and/or enjoyable outside the home such as community recreation and leisure activities (e.g. clubs) and sports, and the freedom to make activity choices were the codes categorized under Participation in Meaningful Activities domain theme, as highlighted in this participant's quote:

“To do things on my own, what I want to do, like get a part time job" [Youth 1].

This participant states it this way:

"One of the first things I had to cut out was training. With modifications, like instead of skiing, I'd go out and do [less physically challenging drills], and still get to hang out with my friends, be outside doing stuff, and at least be part of what I love" [Youth 2]. 
This is an Accepted Manuscript of an article published by Taylor \& Francis in Disability and Rehabilitation on January 2019, available online: http://wwww.tandfonline.com/

$$
10.1080 / 09638288.2018 .1532462 .
$$

Consequently, this domain was defined as engagement in activities that fulfil a personal or culturally important goal or a purpose, in an attempt to improve life satisfaction.

The Program Satisfaction domain was defined as the level of agreement between the youth/parents' perceived results of a program with their preconceived expectations of that same program. This domain theme reflected statements linked to the interdisciplinary care received, the quality and rapport established with professionals, and whether parents' and youth expectations, goals, and needs were met by the services provided. One individual put it this way:

"It's about comprehensiveness. Bringing all these medical experts to us was very satisfying; everyone sharing the same focus on the pain issue...It also was about keeping parents informed about what was happening as my expectations were built into that" [Parent 2].

The outcome domains added as a result of the meeting phases of the NGT (i.e. Step 3 and 4) included: Pain-Related Fear, Anxiety, Focused Attention and Learning, and Memory. Fear of movement, fear of pain, and fear of recurrence associated with pain were codes included in the Pain-Related Fear outcome domain, as summarized by this participant:

"One thing I want to put out there is that fear goes along with pain. Because when the pain gets better and then you have a bad day, there is a fear that you might end up back where [you started]. Like for [my child], who was in a wheelchair, maybe it will happen again" [Parent 1].

Pain-related fear associated with the anticipation of pain related to movement, event or specific situation due to previous experience was the definition attributed to this domain.

This domain was closely associated with the Anxiety outcome domain, defined as the degree of feeling of worry, nervousness, or unease, typically about an event or something with an uncertain outcome, as explained by the same participant: 
This is an Accepted Manuscript of an article published by Taylor \& Francis in Disability and Rehabilitation on January 2019, available online: http://wwww.tandfonline.com/

$$
10.1080 / 09638288.2018 .1532462 .
$$

"Triggers in these kids are much quicker and easier compared to someone who has not experienced the pain. 'Cause they are trying to get better but they might do something, which may lay me up for a few days but for these kids it's a lot more important, because it is a whole lifestyle to go back to. I think it is a trauma of some sort" [Parent 2].

Focused Attention and Learning domain related to statements associated with one's ability to focus on things other than pain, for example homework, acquire new knowledge or to learn or master a new skill (e.g. musical instrument) and did not include distracting strategies (e.g. listening to music or playing video games) often utilized as a pain management strategy.

"In the case of homework, the pain disrupts the focus or more the quality of focus where you are doing things that are adding value to you, like how long you can attend to a task, value added-focus. Not like video games, that are like a distraction when you have pain" [Parent 1].

This domain was defined as the ability to direct and focus to complete any cognitively planned activity, any sequenced action, or any thought process.

The Memory domain was also associated with learning but was specifically related to recalling and remembering information, knowledge or skills previously acquired. The capacity to recognize, recall, remember facts, events, impressions, or previous experiences was adopted as its definition.

The participants also underscored the importance of considering some outcome domains through a developmental lens, as stated by this participant:

"There is a developmental trajectory to all of this. What youth are expected to do and what they want to do is very different at 12 years of age versus 15 , and so on into young adulthood" [Manager 1].

The participant provides another example: 
This is an Accepted Manuscript of an article published by Taylor \& Francis in Disability and Rehabilitation on January 2019, available online: http://wwww.tandfonline.com/

$10.1080 / 09638288.2018 .1532462$.

"My ability to manage my pain in a way that allows me to continue what I'm doing.

It's also important that I'm not limited in what I can do, and that I'm able to operate at or above the level of other people my age." [Youth 1 with Chronic Pain]

This developmental lens was incorporated into the definition of the outcomes domain themes to which it applied. Figure 1 illustrates how the 15 outcome domain themes linked to the ICFCY, and as well as the relationship of themes that did not directly relate to the aforementioned framework.

\section{[Include Figure 1 about here]}

In their descriptions of the outcome domains, participants made links between all of the components of the ICF-CY (as indicated by the arrows in Figure 1), as highlighted in this quote:

"It is about breaking the vicious cycle. She does not get to see her friends and work out, it impacts her sleep. If her sleep gets impacted, then she does not get to school. She does not go to school, then I say: "You can't go do your training, and then [it just keeps cycling" [Parent 1].

At the fifth step (i.e. Voting) of the NGT procedure, all participants completed the online survey distributed. The following outcome domains were prioritised by all 5 stakeholder groups: 1) Activities of Daily Living, 2) Participation in Meaningful Activities, 3) Social Roles and Relationships, and 4) Mood and Affect. Four out of the 5 groups also focused on Self-Efficacy (all except manager) and School Engagement (all except youth). Analysis by stakeholder groups identified some discrepancies in outcome domain rankings. Figure 2 represents, in a two-dimensional format, the multiple outcome domains as prioritized by the youth, parent, clinician, and middle manager stakeholder groups; teachers were not included as they did not prioritize their selection. Twelve outcome domains out of 15 received a ranking score by at least one stakeholder group. Each of these twelve domains 
This is an Accepted Manuscript of an article published by Taylor \& Francis in Disability and Rehabilitation on January 2019, available online: http://wwww.tandfonline.com/

10.1080/09638288.2018.1532462.

forms an individual axis of the graph, which has been arranged radially around a point. The prioritization ranking score for each outcome is depicted by the marker on the axis (a.k.a. spoke); a line has been drawn connecting the data values for each spoke with a different line style (e.g., dashed, solid) representing each of the stakeholder's (i.e. youth, their parents, clinicians and managers) outcome priorities. The closer the marker is to the outer edge of the spoke, the higher the priority, while the more it approximates the centre, the lower the importance. Overlapping markers indicate similar ranking priority for more than one stakeholder group. For example, parents and youth assigned the same level of importance to Participation in Meaningful Activity and to Social Roles and Relationships domains.

[Insert Figure 2 about here]

As illustrated, Pain, Activities of Daily living, Mood and Affect, Social Roles and Relationships, Participation in Meaningful Activities and Self-Efficacy were the outcome domains ranked highest by youth, while parents prioritised, Activities of Daily Living, Sleep, Program Satisfaction, Participation in Meaningful Activities, Social Roles and Relationships and Mood and Affect. Clinicians underscored the outcome domains of Participation in Meaningful Activity, Activities of Daily Living, Engagement in School, Pain-Related Fear, and Self-Efficacy. While middle managers also emphasized Participation in Meaningful Activity, and Activities of Daily Living, they also highlighted Program Satisfaction, Family Functioning, Engagement in School, and Mood and Affect respectively. Finally, as previously mentioned, teachers assigned the same priority to Participation in Meaningful Activity, Activities of Daily Living, Engagement in School, Pain-Related Fear, Social Roles and Relationships and Self-Efficacy, as in their opinion, all were of equal importance.

Based on the set weighted priority cut-off score (i.e. 25 or higher) and the themes ranked highest by the majority of stakeholder groups (i.e. 3 or more), the six final outcome domains prioritized for future effect analysis studies include: 1) Activities of Daily Living, 2) 
This is an Accepted Manuscript of an article published by Taylor \& Francis in Disability and Rehabilitation on January 2019, available online: http://wwww.tandfonline.com/ 10.1080/09638288.2018.1532462.

Participation in Meaningful Activities, 3) Mood and Affect, 4) Social Roles and Relationship,

5) School Engagement, and 6) Self-Efficacy.

\section{Discussion}

This study's primary aim was to generate and prioritize outcome domains, sensitive to the evaluation needs of various stakeholders involved in our IPR programs, including health managers, clinicians, teachers, youth with chronic pain, and their parents. Our stakeholder group identified 15 outcome domains, distributed across the 5 components of the ICF-CY framework. Although differences between stakeholder groups arose, 6 of the domains were prioritised for measurement in a future effect analysis of our context-specific IPR programs. The addition of stakeholders' perspectives is deemed particularly important in the development of outcome sets in order to ensure their relevance and meaningfulness $[36,42,43]$. Moreover, the inclusion of varied perspectives has been found to be effective in identify novel outcomes and provides a unique perspective in their prioritization $[43,44,45,46]$.

The novelty and uniqueness in our stakeholder-identified outcome domains were evident when our findings were compared to those of the PedIMMPACT recommendations [15]. Our stakeholder prioritized domains associated to only three of the eight recommendations. More specifically, the Physical Functioning domain was linked by definition to our Activities of Daily Living domain, Emotional Functioning to our Mood and Affect domain, and Role Functioning related to two of our domains, Social Roles and Relationships and School Engagement. Although our Social Roles and Relationships domain was defined similarly to that of McGrath and colleagues [15], School Engagement was added. School engagement has been demonstrated as a robust predictor of school performance, attendance, and school completion $[47,48]$, areas requiring further exploration in the pediatric chronic pain population [49]. 
This is an Accepted Manuscript of an article published by Taylor \& Francis in Disability and Rehabilitation on January 2019, available online: http://wwww.tandfonline.com/

\subsection{0/09638288.2018.1532462.}

Our study also highlighted other outcome domains, which were not identified previously; these included Self-Efficacy, Participation in Meaningful Activities, and Family Functioning. The emergence of the Resilience-Risk Model for Pediatric Chronic Pain [50] has led to the suggested inclusion of these outcome domains in effectiveness studies. For example, Zernikow and colleagues highlighted the need to further explore the competencies developed during IPR programs [51]. These competencies, and more specifically, the confidence to perform them, could be assessed through the measurement of self-efficacy. Self-efficacy has demonstrated a strong relationship with physical functioning in adolescents with chronic pain, mediating the relationship between pain and physical functioning $[52,53]$. Participation in meaningful activities, also suggested as a key outcome (i.e. perseverance with valued activities) in the Resilience-Risk Model [49], is critical to psychological flexibility, pain acceptance, enables commitment to goal-directed action [54,55], and is vital to building competencies in youth [51]. Few studies have considered the impact of IPR programs of the development of adequate competencies, which impact adolescents' abilities to engage in activities, and develop the attributed necessary to manage their pain [56]. Finally, family functioning, an additional resilience resource, has been suggested as a protective factor in promoting higher functioning among youth with a variety of chronic pain conditions [17,57], and may improve pain self-management, coping, and adjustment in youth with chronic pain [50]. Although the importance of Family Functioning continues to be underscored in the literature [57] and was identified as an outcome domain by our stakeholders, it did not achieve priority status amongst the majority of the stakeholder groups. This may be due to the recognition of the lack of an appropriate measurement tool able to capture the impact of specific family processes over time or a belief that a longer episode of care than is typically available in IPR programs, is required to influence family functioning. The list of outcome domains generated from our findings could be used in designing future context-specific IPR 
This is an Accepted Manuscript of an article published by Taylor \& Francis in Disability and Rehabilitation on January 2019, available online: http://wwww.tandfonline.com/

\subsection{0/09638288.2018.1532462.}

program evaluations, serving as a guide for stakeholders in their prioritization of outcomes to be measured. However, it must be recognized that the focus of the study (e.g. youth centered versus family centered) and the stakeholders involved may alter the choice of outcome domains.

Our use of the ICF-CY framework allowed a broader conceptualization of the scope of disability and function than traditionally represented in pain-related outcome domains. In addition to underscoring the breadth of our context-specific stakeholder concerns, it confirmed the far-reaching disabling consequences of pediatric chronic pain on youth and their families. Moreover, it suggests a need to describe these effects using a recognized "disability" framework, which could offer further guidance in the formulation of IPR program objectives and targeted outcomes and expands the choice of measurement tools available to capture stakeholder-prioritized outcome domains. Our stakeholders prioritized outcome domains most frequently linked to the Activity (i.e. the execution of tasks or actions) and Participation (i.e. one's involvement in real life situations) components of the ICF-CY. This suggests that stakeholders, despite their background, consider participation in life and its related activities as key desired outcomes of IPR programs; a concept that aligns with other paediatrics rehabilitation studies [32,35]. Recently, Kempert and colleagues identified a lack of specific rehabilitation outcomes to track physical functioning [58]. An array of clinically relevant physical functioning measures exist in pediatric rehabilitation for youth with disabilities (e.g.. the School Function Assessment (SFA) [59], Participation and Environment Measure for Children and Youth (PEM-CY) [60]), which, once validated, could be applied to youth with pain-related disability, filling an important measurement gap.

Finally, our study also provides valuable information about the feasibility of using a formalized consensus method in selecting program outcomes with a diverse group of stakeholders. Unlike the Delphi method, the NGT process has been commonly used with lay 
This is an Accepted Manuscript of an article published by Taylor \& Francis in Disability and Rehabilitation on January 2019, available online: http://wwww.tandfonline.com/

\subsection{0/09638288.2018.1532462.}

persons and their carers, requires minimal pre-meeting preparation, is time-efficient, and relies on active input and face-to-face discussion amongst participants to achieve its goal [32]. Active dialogue in a heterogeneous stakeholder group is critical in establishing a comfort level amongst lay persons and empowering them, fostering respect for all ways of knowing, developing partnerships, and promoting mutual learning across stakeholder groups $[28,60]$. However, our findings also demonstrated the importance of incorporating individual anonymous strategies to ensure valid results, reflecting the authentic perspective of each participant and minimizing participant response bias. Frequencies fluctuations in outcome domains generated from the individual responses to the NGT question (Table 2) to those prioritized following the voting process (Figure 2) were apparent. For example, Participation in Meaningful Activities was initially identified by a small number of participants yet achieved a high priority score in the voting process, while Pain, although identified by a variety of stakeholders in the initial NGT question responses, decreased in ranking with all stakeholders throughout the process, except for youth with a history of pain-related disability. With the growing consensus about the crucial role of patient and caregiver involvement in improving the value of healthcare research, and quality and safety in the healthcare system [61], and the mounting requests by funding agencies to show evidence of genuine consumer involvement [62], this study suggests that the NGT method engages stakeholders, and allows authentic stakeholder perspectives and opinions to be voiced. However, replication of this method in other contexts is needed to ensure its generalizability to multiple milieus, and the broader application of these outcome domains across IPR programs.

Several limitations exist in this study. First, although deemed a representative sample, the selection of the participants was restricted to those who were identified by hospital leadership and school administrative teams and therefore may limit the variability in our sample. Indeed, individuals approached may have shared similar characteristics and 
This is an Accepted Manuscript of an article published by Taylor \& Francis in Disability and Rehabilitation on January 2019, available online: http://wwww.tandfonline.com/

\section{$10.1080 / 09638288.2018 .1532462$.}

perspectives about what should be valued in such interventions. Secondly, stakeholder groups had an unequal member distribution due to the volunteer nature of study participation, and therefore weighting of our results was required. Although weighting equalized the influence of each stakeholder group limiting the underestimation of outcomes valued by more marginal groups (e.g. healthcare manager), we did assume that any additional participants would agree with the outcome domain prioritized by their associated stakeholder group representative which may not be the case. Thirdly, in adhering to the recommendations for consensus methods, where the study sample should reflect the perspective of a range of stakeholders interested in the results of the study [26], our participant sample was intrinsically linked to the context of our study. Consequently, generalization to other IPR programs may be limited. Future studies may consider incorporating a sample of community stakeholders (e.g. coaches, peers, and siblings), an equal and larger number of participants in each group, and one with greater geographical variability. However, increasing the sample should be carefully considered, as samples that are too large are reported to diminish the return due to coordination issues that may ensue $[31,62]$.

Core outcome domains and measures for a particular condition have a finite lifespan. With the recent expansion in scientific discoveries in pediatric chronic pain, and the advancing conceptualisation of this condition, revisiting previously published recommendations is timely. Our study findings highlight differing perspectives on what is valued as outcomes for youth with pain-related disability, underscoring the need to consult an inclusive group of stakeholders in designing program evaluations targeting this population. It also raises a widening measurement gap in outcome measures sensitive to some stakeholder priorities. Lastly, with the growing focus on patient engagement in research in many countries (e.g. United States, United Kingdom), the NGT process framed in the ICF-CY framework used in this study holds promise as a method capable of promoting mutual 
This is an Accepted Manuscript of an article published by Taylor \& Francis in Disability and Rehabilitation on January 2019, available online: http://wwww.tandfonline.com/

$$
10.1080 / 09638288.2018 .1532462 .
$$

learning among stakeholders, while ensuring the authenticity of their perspectives, when a context-specific group of diverse stakeholders is involved.

Acknowledgements: We would like to thank all the stakeholders who so willingly shared their opinions, expertise, and time with us. In addition, we would also like to acknowledge Dr. Laura Brunton for her knowledge and assistance with the International Classification of Function linking process. Finally, we would like to extend our gratitude to the funding agencies (Vanier Doctoral Scholarship Award) and the training programs (Canadian Child Health Clinician Scientist Program, Pain in Child Health: Research Training Initiative) that support the first author.

Conflict of Interest: The authors report no conflicts of interest. 
This is an Accepted Manuscript of an article published by Taylor \& Francis in Disability and Rehabilitation on January 2019, available online: http://wwww.tandfonline.com/

$10.1080 / 09638288.2018 .1532462$.

\section{References}

[1] Forgeron, P., King, S., Stinson, J., McGrath, P., MacDonald, A., \& Chambers, C. Social functioning and peer relationships in children and adolescents with chronic pain: A systematic review. Pain Research \& Management. 2010; 15(1): 27-41.

[2] Huguet, A., \& Miró, J. The severity of chronic pediatric pain: An epidemiological study. The Journal of Pain. 2008; 9(3):226-236.

[3] Lewandowski Holley, A., Law, E., Zhou, C., Murphy, L., Clarke, G., \& Palermo, T. Reciprocal longitudinal associations between pain and depressive symptoms in adolescents. European Journal of Pain. 2013; 17 (7): 1058-1067.

[4] Noel, M., Groenewald, N., Beals-Erikson, S., Gebett, J., Palermo, T. Chronic Pain in adolescents and internalizing mental health disorders, in adulthood: A national representative study. PAIN. 2016; 157 (6): 1333-1338. 
This is an Accepted Manuscript of an article published by Taylor \& Francis in Disability and Rehabilitation on January 2019, available online: http://wwww.tandfonline.com/

10.1080/09638288.2018.1532462.

[5] Hechler, T., Kanstrup, M., Holley, A. L., Simons, L. E., Wicksell, R., Hirschfeld, G., et al. Systematic review on intensive interdisciplinary pain treatment of children with chronic pain. Pediatrics. 2015; 136 (1): 115-127.

[6] World Health Organization. International classification of functioning, disability, and health: Children \& youth version: ICF-CY. Geneva, Switzerland. World Health Organization. 2007.

[7] Löwing, K., Hamer, E., Brexelius, A.M., Brogren Carlberg, E. Exploring the relationship of family goals and scores on standardized measures in children with cerebral palsy, using the ICF-CY. Developmental Neurorehabilitation. 2011; 14(2): 79-86.

[8] Cross, A., Rosenbaum, P., Grahovac, D., Kay, D., Gorter, J. Knowledge mobilization to spread awareness of 'F-words' in childhood disability: lessons from a familyresearcher partnership. CHILD: Care, health and development. 2015; 41(6): 947-953.

[9] Rosenbaum, P. Stewart, D., The World Health Organization International Classification of Function, Disability, and Health: A model to guide clinical thinking, practice and research in cerebral palsy. Seminars of Pediatric Neurology. 204; 11: 510.

[10] Boutier, J. \& King, S. Missed opportunities: School as an undervalued site for effective pain management. Pediatric Pain Letter: Commentaries on pain in infants, children, and adolescents. 2013; 15 (1): 9-15.

[11] Lamontagne, M., Swaine, B., Lavoie, A., Champagne, F., Marcotte, A. Consensus group sessions: a useful method to reconcile stakeholders' perceptive about network performance evaluation. International Journal of Integrated Care. 2010; 10: 1-10.

[12] Klassen, A., Miller, A., Anderson, N., Shen, J., Schiariti, V., O’Donnel, M. Performance Measurement and Improvement Frameworks in Health, Education and 
This is an Accepted Manuscript of an article published by Taylor \& Francis in Disability and Rehabilitation on January 2019, available online: http://wwww.tandfonline.com/

10.1080/09638288.2018.1532462.

Social Services Systems: A Systematic Review. International Journal of Quality in Health Care. 2010; 22 (1): 44-69.

[13] Reeve, J. \& Peerbhoy, D. Evaluating the evaluation: Understanding the utility and limitation of evaluation as a tool for organizational learning. Health Education Journal. 2017; 66 (2): 120-131.

[14] Chen, H. T. Practical program evaluation: Theory-driven evaluation and the integrated evaluation perspective ( $2^{\text {nd }}$ Edition). SAGE Publications. 2014.

[15] McGrath, P., Walk, G., Turk, D., Dworkin, R., Brown, M., Davidson, K., et al. Core outcome domains and measures for pediatric acute and chronic/recurrent pain clinical trials: PedIMMPACT recommendations. The Journal of Pain. 2008; 9(9): 771-783.

[16] Sacristán, J. A. (2013). Patient-centered medicine and patient-oriented research: improving health outcomes for individual patients. BMC medical informatics and decision making. 2013;13(1): 6 .

[17] Logan, D. E., Simons, L. E., Stein, M. J., \& Chastain, L. School impairment in adolescents with chronic pain. The Journal of Pain, 2008. 9(5), 407-416.

[18] Eccleston, C., Wastell, S., Crombez, G., \& Jordan, A. Adolescent social development and chronic pain. European Journal of Pain. 2008; 12(6): 765-774.

[19] Logan, D. E., Coakley, R. M., \& Scharff, L. Teachers' perceptions of and responses to adolescents with chronic pain syndromes. Journal of pediatric psychology. 2008; 32(2): 139-149.

[20] Camden, C., Shikako-Thomas, K., Nguyen, T., Graham, E., Thomas, A., Sprung, J., et al. Engaging stakeholders in rehabilitation research: a scoping review of strategies used in partnerships and evaluation of impacts. Disability and rehabilitation. 2015; 37(15): 1390-1400. 
This is an Accepted Manuscript of an article published by Taylor \& Francis in Disability and Rehabilitation on January 2019, available online: http://wwww.tandfonline.com/ $10.1080 / 09638288.2018 .1532462$.

[21] Birken, S. A., Lee, S. Y. D., \& Weiner, B. J. Uncovering middle managers' role in healthcare innovation implementation. Implementation Science. 2012;7(1): 28.

[22] Gagliardi, Anna R., and Mark J. Dobrow. Identifying the conditions needed for integrated knowledge translation (IKT) in health care organizations: qualitative interviews with researchers and research users." BMC health services research. 2016;16 (1): 256.

[23] Engle, R. L., Lopez, E. R., Gormley, K. E., Chan, J. A., Charns, M. P., \& Lukas, C. V. What roles do middle managers play in implementation of innovative practices? Health care management review. 2017; 42(1): 14.

[24] Morris, C., Shilling, V., McHugh, C., \& Wyatt, K. Why it is crucial to involve families in all stages of childhood disability research. Developmental Medicine \& Child Neurology. 2011; 53(8): 769-771.

[25] Rosenbaum, P. Family-centred research: what does it mean and can we do it? Developmental Medicine \& Child Neurology. 2011; 53(2): 99-100.

[26] Fink, A., Kosecoff, J., Chassin, M., \& Brook, R. H. Consensus methods: Characteristics and guidelines for use. American Journal of Public Health. 1984; 74(9): 979-983.

[27] MacPhail, A. Nominal group technique: A useful method for working with young people. British Educational Research Journal. 2001; 27(2):161-170.

[28] Cieza, A., Geyh, S., Chatterji, S., Kostanjsek, N., Üstün, B., Stucki, G. ICF linking rules: an update based on lessons learned. Journal of Rehabilitation Medicine. 2005; 37: 212-218.

[29] Miles, M.B., Huberman, A.M., Saldana, J. Qualitative Data Analysis: A Methods Sourcebook ( $3^{\text {rd }}$ Edition). SAGE Publication Inc., London, UK. 2014. 
This is an Accepted Manuscript of an article published by Taylor \& Francis in Disability and Rehabilitation on January 2019, available online: http://wwww.tandfonline.com/ $10.1080 / 09638288.2018 .1532462$.

[30] Boulkedid, R., Abdoul, H., Loustau, M. Using and reporting the Delphi method for selecting health care indicators: A systematic reviw. PLoS ONE. 2016; 6(6): e20476. Doi:10.1371/journal. pone.0020476

[31] McMillan, S., King, M., Tully, M. How to use the nominal group and Delphi techniques. Int J Clin Pharm. 2016; 38: 655-662.

[32] Potter, M., Gordon, S., \& Hamer, P. The nominal group technique: A useful consensus methodology in physiotherapy research. New Zealand Journal of Physiotherapy.2004; 32: 126-130.

[33] Peng, P., Stinson, J. N., Choiniere, M., Dion, D., Intrater, H., LeFort, S., et al. Dedicated multidisciplinary pain management centres for children in Canada: the current status. Canadian Journal of Anaesthesia. 2007; 54(12): 985.

[34] Stahlschmidt, L., Zernikow, B., \& Wager, J. Specialized rehabilitation programs for children and adolescents with severe disabling chronic pain: indications, treatment and outcomes. Children. 2016; 3(4): 33.

[35] Löwing, K., Hamer, E., Brexelius, A.M., Brogren Carlberg, E. Exploring the relationship of family goals and scores on standardized measures in children with cerebral palsy, using the ICF-CY. Developmental Neurorehabilitation. 2011; 14(2): $79-86$.

[36] Heiligenhaus, A., Foeldvari, I., Edelsten, C., Smith, J. R., Saurenmann, R. K., Bodaghi, B., et al. Proposed outcome measures for prospective clinical trials in juvenile idiopathic arthritis-associated uveitis: A consensus effort from the multinational interdisciplinary working group for uveitis in childhood. Arthritis care \& research. 2012; 64(9):1365-1372. 
This is an Accepted Manuscript of an article published by Taylor \& Francis in Disability and Rehabilitation on January 2019, available online: http://wwww.tandfonline.com/ $10.1080 / 09638288.2018 .1532462$.

[37] Wainwright, D., Boichat, C., \& McCracken, L. M. Using the nominal group technique to engage people with chronic pain in health service development. The international journal of health planning and management. 2014; 29(1): 52-69.

[38] Wallace, S. J., Worrall, L., Rose, T., Le Dorze, G., Cruice, M., Isaksen, J.et al. Which outcomes are most important to people with aphasia and their families? An international nominal group technique study framed within the ICF. Disability and rehabilitation. 2017; 39(14): 1364-1379.

[39] Vargus-Adams, J. \& Martin, L. Measuring what matters in cerebral palsy: A breath of important domains and outcome measures. Archives of Physical Medicine and Rehabilitation. 2009; 90: 2089-95.

[40] Rosenbaum, P., \& Gorter, J. W. The 'F-words' in childhood disability: I swear this is how we should think! Child: Care, Health and Development. 2012;38 (4):457-463.

[41] World Health Organization. International classification of function, disability, and health. Geneva, Switzerland. World Health Organization. 2001.

[42] Applied Survey Methods - Statistical Perspective, Survey Methods, Weighted Adjustments. Retrieved May 2017 from http://www.applied-surveymethods.com/weight.html.

[43] di Wit, M., Abma, T., Koelewijn-van Loon,M., Collins, S, Kirwin, J. What has been the effect on trial outcome assessments of a decade of patient participation in OMERACT? Journal of Rheumatology. 2013; 41(1): 177-184.

[44] Williamson, P. R., Altman, D. G., Blazeby, J. M., Clarke, M., Devane, D., Gargon, E., \& Tugwell, P. Developing core outcome sets for clinical trials: issues to consider. Trials. 2012; 13(1): 132. 
This is an Accepted Manuscript of an article published by Taylor \& Francis in Disability and Rehabilitation on January 2019, available online: http://wwww.tandfonline.com/ 10.1080/09638288.2018.1532462.

[45] Arnold, L., Crofford, L., Mease, P., Burgess, S., Palmer, S, Abetz, L., Martin, S. (2008). Patient perspectives on the impact of fibromyalgia. Patient Education and Counselling. 73 (1): 114-120.

[46] Carr, A, Hewett, S., Hughes, R., Mitchell, H., Ryan, S, Carr, M., Kirwin, J. Rheumatology outcomes: the patient perspective. Journal of Rheumatology. 2003; 30(4): $880-883$.

[47] Mease, P., Arnold, L., Crofford, L., Williams, D., Russell, I, Humphrey, L. et al. Identifying the clinical domains of fibromyalgia: contributions from clinician and patient Delphi exercise. Arthritis Care and Research. 2009; 59(7): 952-960.

[48] Saunderson, T., Morris, M., Calnan, M., Richards, P, Hewlett, S. What outcomes from pharmacologic treatment are important to people with rheumatoid arthritis? Creating the basis of a patient core set. Arthritis care resident (Hoboken). 2010; 62: 640-646.

[49] Appelton, J., Christenson,S., Furlong, M. Student engagement with school: Critical conceptual and methodological issues of the construct. Psychology in Schools. 2008; 45(5): 369-386.

[50] Agoston, A, Gray, L., Logan, D. Pain in School: Patterns of pain related impairment among adolescents with primary pain conditions, juvenile arthritis, and pain-free peers. Children. 2016; 31(4): 1-9.

[51] Shernoff, D., \& Schmidt, J. Further evidence of an engagement-achievement paradox among U.S. high school students. Journal of Youth and Adolescence. 2009; 37(5): 564-580.

[52] Cousins, L., Kalapurakkel, S., Cohen, L., Simons, L. Topical Review: Resilience resources and mechanisms in pediatric chronic pain. Journal of Pediatric Psychology. 2015; 40(1): 840-845. 
This is an Accepted Manuscript of an article published by Taylor \& Francis in Disability and Rehabilitation on January 2019, available online: http://wwww.tandfonline.com/ 10.1080/09638288.2018.1532462.

[53] Zernikow, B., Ruhe, A.M., Stahlschmidt, L., Schmidt, P., Staratzke, T., Frosche, M., Wagner, J. Clinical and economic long-term treatment outcomes in children and adolescents with disabling chronic pain. Pain Medicine. 2017; 00: 1-13.

[54] Carpino, E., Segal, S., Logan, D., Lebel, A., Simons, L. The interplay of pain-related self-efficacy and fear on functional outcomes among youth with headache. Journal of Pain. 2014; 15(5): 527-534.

[55] Kalapurakkel, S., Carpino, E., Lebel, A., Simons, L. Pain Can’t Stop Me”: Examining pain self-efficacy and acceptance as resilience processes among youth with chronic headache. Journal of Pediatric Psychology. 2015; 40(9): 926-933.

[56] McCraken L. Committed action: An application of the psychological flexibility model to activity patterns in chronic pain. The Journal of Pain. 2013;14 (8): 828-835.

[57] McCraken, L. \& Morley, S. The psychological flexibility model: A basis for integration and progress in psychological approaches to chronic pain management. The Journal of Pain. 2014; 15(3): 221-234.

[58] Sinclair, C. Meredith, P., Strong, J., Feeney, B. Personal and contextual factors affecting the functional ability of children and adolescents with chronic pain: A systematic review. Journal of Development and Behaviour in Pediatrics. 2016; 37: $327-342$.

[59] Palermo, T. M., Valrie, C. R., \& Karlson, C. W. Family and parent influences on pediatric chronic pain: A developmental perspective. American Psychologist. 2014; 69 (2): 142-152.

[60] Kempert, H., Benore, E., Heines, R. Physical and occupational therapy outcomes: Adolescents' change in functional abilities using objective measures and self-report. Scandinavian Journal of Pain. 2017; 14: 60-66. 
This is an Accepted Manuscript of an article published by Taylor \& Francis in Disability and Rehabilitation on January 2019, available online: http://wwww.tandfonline.com/ 10.1080/09638288.2018.1532462.

[61] Coster, W., Deeney, T.A, Haltiwanger, J.T., Haley, S.M. School function assessment user's manual. Therapy Skill Builders, San Antonio. 1998.

[62] Coster, W., Bedell, G., Law, M., Khetani, M., Teplicky, R., Liljenquist, K. et al. Psychometric evaluation of the Participation and Environment Measure for Children and Youth, Developmental Medicine and Child Neurolology. 2011; 53:1030-1037.

[63] Domecq, J., Prustsky, G., Eltaiyah, T., Wang, Z., Nabhan, M., Shippee, N. Brito, J., Boehmer, et al. Patient engagement in research: A systematic review. BMC Health Services Research. 2014; 14(89): 1- 9.

[64] Carman, K., Dardes, P., Maurer, M., Sofaer, S., Adams, K., Bechtel, C., Sweeney, J. Patient and family engagement: A framework for understanding the elements and developing interventions and policies. Health Affairs. 2013;32(2): 223-231. 
This is an Accepted Manuscript of an article published by Taylor \& Francis in Disability and Rehabilitation on January 2019, available online: http://wwww.tandfonline.com/

10.1080/09638288.2018.1532462.

\begin{tabular}{|c|c|c|c|c|c|}
\hline $\begin{array}{l}\text { Stakeholder } \\
\text { Group }\end{array}$ & $\begin{array}{c}\text { Health } \\
\underline{\text { Manager }} \\
(\mathrm{n}=2)\end{array}$ & $\begin{array}{l}\text { Teacher } \\
\underline{(n=2)}\end{array}$ & $\begin{array}{l}\underline{\text { Clinicians }} \\
\underline{(n=5)}\end{array}$ & $\begin{array}{l}\underline{\text { Parents }} \\
\underline{(n=2)}\end{array}$ & $\begin{array}{l}\text { Youth } \\
\underline{(\mathrm{n}=2)}\end{array}$ \\
\hline \multicolumn{6}{|c|}{ Age - number of participants (frequency) } \\
\hline 51 years > & - & $2(100 \%)$ & - & $2(100 \%)$ & - \\
\hline $41-50$ years & $1(50 \%)$ & - & $2(40 \%)$ & - & - \\
\hline $31-40$ years & $1(50 \%)$ & - & $3(60 \%)$ & - & - \\
\hline$<30$ years & - & - & - & - & $2(100 \%)$ \\
\hline \multicolumn{6}{|c|}{ Gender - number participants (frequency) } \\
\hline Female & $2(100 \%)$ & $2(100 \%)$ & $4(80 \%)$ & $1(50 \%)$ & $1(50 \%)$ \\
\hline Male & - & - & $1(20 \%)$ & $1(50 \%)$ & $1(50 \%)$ \\
\hline \multicolumn{6}{|c|}{ Years of working with youth - number participants (frequency) } \\
\hline 10 years $>$ & $2(100 \%)$ & $2(100 \%)$ & $3(60 \%)$ & $2(100 \%)$ & N/A \\
\hline 6-10 years & - & - & $2(40 \%)$ & - & N/A \\
\hline \multicolumn{6}{|c|}{$\begin{array}{l}\text { Years of experience with youth with chronic pain - number of participants } \\
\text { (frequency) }\end{array}$} \\
\hline 10 years $>$ & $2(100 \%)$ & $1(50 \%)$ & $1(20 \%)$ & - & - \\
\hline $6-10$ years & & - & $3(60 \%)$ & $1(50 \%)$ & N/A \\
\hline $3-5$ years & & $1(50 \%)$ & $1(20 \%)$ & $1(50 \%)$ & N/A \\
\hline
\end{tabular}

Table 1. Participant Characteristics 
This is an Accepted Manuscript of an article published by Taylor \& Francis in Disability and Rehabilitation on January 2019, available online: http://wwww.tandfonline.com/

10.1080/09638288.2018.1532462.

\begin{tabular}{|c|c|c|}
\hline Steps & Procedures & Analysis \\
\hline $\begin{array}{l}\text { Step } 1 . \\
\text { Introduction to a } \\
\text { framework to } \\
\text { establish a } \\
\text { common } \\
\text { language }\end{array}$ & $\begin{array}{l}\text { A version of an evaluated online video [38] } \\
\text { introducing and explaining the "F-words" in } \\
\text { Childhood Disability [36], a series of words } \\
\text { beginning with "f" (Fitness, Function, Family, } \\
\text { Friends, Fun and Future) representative of the } \\
\text { International Classification of Function (ICF) } \\
\text { [37] domains, was presented to clinicians, } \\
\text { teachers, and managers, and each parent-youth } \\
\text { dyad. } \\
\text { Relevance of the framework within the group, } \\
\text { participants was established by multiple } \\
\text { examples of the impact of pain-related } \\
\text { disability within each of the domains being } \\
\text { generated by all stakeholder group. }\end{array}$ & \\
\hline $\begin{array}{l}\text { Step 2. Idea } \\
\text { Generation }\end{array}$ & $\begin{array}{l}\text { The aforementioned NGT question was } \\
\text { distributed to participants via email, who was } \\
\text { then asked to generate as many ideas as } \\
\text { possible related to the question and returned } \\
\text { them to the research team }\end{array}$ & $\begin{array}{l}\text { Using content analysis, } \\
\text { recorded ideas were } \\
\text { themed into outcome } \\
\text { domains by two research } \\
\text { team members; } \\
\text { frequencies were then } \\
\text { calculated (see Table } 3 \text { ). }\end{array}$ \\
\hline $\begin{array}{l}\text { Step 3. Idea } \\
\text { Recording and } \\
\text { Step 4. Idea } \\
\text { Clarification } \\
\text { (cont.) }\end{array}$ & $\begin{array}{l}\text { Due to scheduling conflicts, two } 90 \text {-minute } \\
\text { sequential face-to-face meetings were } \\
\text { organized; participants were asked to attend } \\
\text { one. Representatives from each stakeholder } \\
\text { groups were present at the meetings. } \\
\text { At the first meeting (including } 6 \text { participants), } \\
\text { a research team member, experienced in } \\
\text { facilitation (KH) presented each generated } \\
\text { theme on a flip chart sheet and invited } \\
\text { everyone to add clarity. Any additional ideas } \\
\text { were recorded. Elimination of items was not } \\
\text { permitted; however further theming of the } \\
\text { domains occurred when two or more domains } \\
\text { represented the same concept. } \\
\text { The second meeting (including } 7 \text { participants) } \\
\text { began with the review of each theme and its } \\
\text { summary from the first meeting. Further } \\
\text { clarification by participant, and additional idea } \\
\text { recording as per the first meeting was } \\
\text { encouraged, in conjunction with theming. } \\
\text { Domain definitions, emerging during the } \\
\text { discussion were recorded during the meeting } \\
\text { and finalised by the research team through two } \\
\text { processes: } 1 \text { ) a peer debriefing process, where } \\
\text { a researcher familiar with pediatric chronic }\end{array}$ & \\
\hline
\end{tabular}


This is an Accepted Manuscript of an article published by Taylor \& Francis in Disability and Rehabilitation on January 2019, available online: http://wwww.tandfonline.com/

$$
10.1080 / 09638288.2018 .1532462 \text {. }
$$

\begin{tabular}{|c|c|c|}
\hline & $\begin{array}{l}\text { pain outcome literature, yet not in attendance at } \\
\text { the participant meetings reviewed the themes } \\
\text { and definitions for comprehensiveness and } \\
\text { clarity; and 2) a member-checking process, } \\
\text { where a participant from the first group } \\
\text { meeting reviewed the themes and definitions } \\
\text { generated at the end of the second meeting. }\end{array}$ & $\begin{array}{l}\text { All outcome domains } \\
\text { themes were linked to } \\
\text { the ICF using an } \\
\text { established linking } \\
\text { procedure [24] (see } \\
\text { Figure 2) }\end{array}$ \\
\hline Step 5. Voting & $\begin{array}{l}\text { An online survey was then created using the } \\
\text { identified outcome domain themes and their } \\
\text { definitions and distributed to the participants. } \\
\text { Participants were given } 2 \text {-weeks to select and } \\
\text { rank outcome domain themes in order of } \\
\text { importance, using a 6-point Likert scale (with } 1 \\
=\text { least important domain and } 6=\text { most } \\
\text { important domain), as participants decided that } \\
6 \text { outcome domains would be selected. } \\
\text { Evidence suggests that the number of items } \\
\text { chosen by participants depends on the topic but } \\
\text { ranking of five to six is common [26]. } \\
\text { The survey results were presented to the } \\
\text { participants at a final meeting to ensure } \\
\text { consensus, defined an outcomes domain theme } \\
\text { achieving a weighted priority cut-off score of } \\
25 \text { or higher, and ranking highest with } 3 \text { groups } \\
\text { or more stakeholder groups. }\end{array}$ & $\begin{array}{l}\text { Priority scores was } \\
\text { calculated as a product } \\
\text { of the number of votes } \\
\text { per domain and the } \\
\text { domain ranking (from } 1 \\
\text { to 6). }\end{array}$ \\
\hline
\end{tabular}

Table 2. Nominal group procedure and data analysis 
This is an Accepted Manuscript of an article published by Taylor \& Francis in Disability and Rehabilitation on January 2019, available online: http://wwww.tandfonline.com/

10.1080/09638288.2018.1532462.

\begin{tabular}{|c|c|c|c|}
\hline Outcome Domain Themes & $\begin{array}{c}\text { Responses/Type(s) } \\
\text { of Stakeholder }\end{array}$ & $\begin{array}{c}\text { Total number of } \\
\text { Responses }\end{array}$ & Frequency \\
\hline Activities of Daily Living & $\begin{array}{c}\text { Clinicians }(\mathrm{n}=5) \\
\text { Managers }(\mathrm{n}=2) \\
\text { Youth }(\mathrm{n}=2) \\
\text { Parents }(\mathrm{n}=1) \\
\text { Teachers }(\mathrm{n}=2) \\
\end{array}$ & 13 & $100 \%$ \\
\hline Self-Efficacy & $\begin{array}{c}\text { Clinicians }(n=2) \\
\text { Managers }(n=2) \\
\text { Teachers }(n=2) \\
\text { Youth }(n=1)\end{array}$ & 7 & $55 \%$ \\
\hline Quality of Life & $\begin{array}{c}\text { Clinicians }(\mathrm{n}=3) \\
\text { Parents }(\mathrm{n}=1) \\
\text { Youth }(\mathrm{n}=1) \\
\text { Managers }(\mathrm{n}=1)\end{array}$ & 6 & $45 \%$ \\
\hline School Engagement & $\begin{array}{c}\text { Clinicians }(\mathrm{n}=1) \\
\text { Teachers }(\mathrm{n}=2) \\
\text { Parents }(\mathrm{n}=1) \\
\text { Youth }(\mathrm{n}=1)\end{array}$ & 5 & $38 \%$ \\
\hline Mood and Affect & Clinicians $(n=4)$ & 4 & $31 \%$ \\
\hline $\begin{array}{l}\text { Social Roles and } \\
\text { Relationships }\end{array}$ & $\begin{array}{c}\text { Clinicians }(n=2) \\
\text { Youth }(n=1) \\
\text { Parents }(n=1)\end{array}$ & 4 & $31 \%$ \\
\hline Family Functioning & $\begin{array}{l}\text { Managers }(n=2) \\
\text { Clinicians }(n=2)\end{array}$ & 4 & $31 \%$ \\
\hline Pain & $\begin{array}{c}\text { Youth }(n=1) \\
\text { Parent }(n=1) \\
\text { Clinicians }(n=2)\end{array}$ & 4 & $31 \%$ \\
\hline $\begin{array}{l}\text { Participation in } \\
\text { Meaningful Activities }\end{array}$ & $\begin{array}{l}\text { Clinician }(\mathrm{n}=1) \\
\text { Youth }(\mathrm{n}=1) \\
\text { Parents }(\mathrm{n}=1)\end{array}$ & 3 & $23 \%$ \\
\hline Sleep & $\begin{array}{l}\text { Parents }(\mathrm{n}=1) \\
\text { Youth }(\mathrm{n}=1)\end{array}$ & 2 & $15 \%$ \\
\hline Program Satisfaction & Clinician $(n=1)$ & 1 & $8 \%$ \\
\hline
\end{tabular}

Table 3. Emerging outcome domains from NGT Question Responses 
This is an Accepted Manuscript of an article published by Taylor \& Francis in Disability and Rehabilitation on January 2019, available online: http://wwww.tandfonline.com/

10.1080/09638288.2018.1532462.

\begin{tabular}{|c|c|c|}
\hline $\begin{array}{c}\text { ICF-CY Component \& } \\
\text { Categories }\end{array}$ & Themes & Codes \\
\hline $\begin{array}{l}\text { Body Function } \\
\text { - Sensory } \\
\text { Function and } \\
\text { Pain } \\
\end{array}$ & $\begin{array}{l}\text { - Pain } \\
\text { - Anxiety } \\
\text { - Pain-related } \\
\text { Fear } \\
\text { - Mood \& Affect } \\
\text { - Sleep } \\
\text { - Memory }\end{array}$ & $\begin{array}{l}\text { - Intensity, frequency, } \\
\text { duration } \\
\text { - } \text { Impact on life } \\
\text { - Focus and described in } \\
\text { personal identity } \\
\text { - Worry, nervousness, } \\
\text { unease } \\
\text { - Fear, fear of movement, } \\
\text { fear of recurrence, } \\
\text { trauma } \\
\text { - Depression, energy, } \\
\text { posture, demeanor } \\
\text { - } \begin{array}{l}\text { Ability to get to sleep \& } \\
\text { stay asleep }\end{array} \\
\text { Ability to recall or } \\
\text { remember knowledge } \\
\text { and previous acquired } \\
\text { skills }\end{array}$ \\
\hline 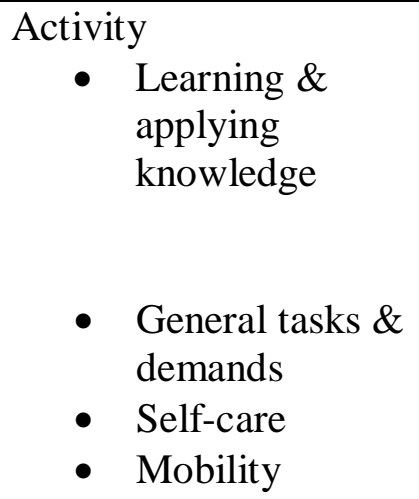 & $\begin{array}{l}\text { - Focused } \\
\text { attention \& } \\
\text { learning } \\
\text { - Activity of daily } \\
\text { living }\end{array}$ & $\begin{array}{l}\text { - Maintain focus to } \\
\text { complete a task/activity, } \\
\text { acquire knowledge or } \\
\text { learn/master a new skill } \\
\text { - Daily Routine } \\
\text { - Self-Care } \\
\text { - Ambulation } \\
\text { - Community Mobility }\end{array}$ \\
\hline $\begin{array}{l}\text { Participation } \\
\text { - } \quad \text { Interpersonal } \\
\text { interactions and } \\
\text { relationships }\end{array}$ & $\begin{array}{l}\text { - Social roles \& } \\
\text { relationships }\end{array}$ & $\begin{array}{ll}\text { - } & \text { Household chores } \\
\text { - } & \text { Friends and friendships } \\
\text { - } & \text { Relationship with }\end{array}$ \\
\hline
\end{tabular}


This is an Accepted Manuscript of an article published by Taylor \& Francis in Disability and Rehabilitation on January 2019, available online: http://wwww.tandfonline.com/

10.1080/09638288.2018.1532462.

\begin{tabular}{|c|c|c|}
\hline $\begin{array}{l}- \text { Major life areas } \\
\\
\text { - Community \& } \\
\text { civic } \\
\text { environments }\end{array}$ & $\begin{array}{l}\text { - School } \\
\text { engagement } \\
\text { - } \begin{array}{l}\text { Participation in } \\
\text { meaningful } \\
\text { activities }\end{array}\end{array}$ & 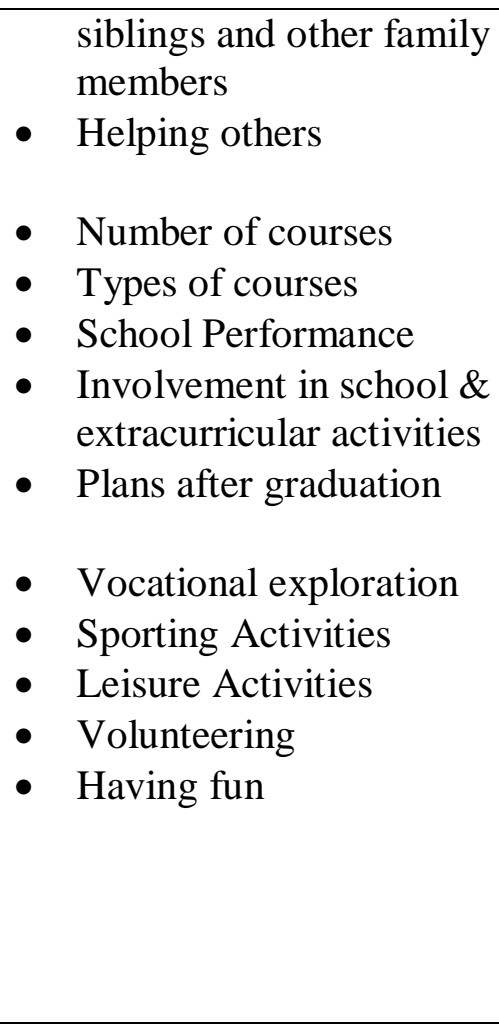 \\
\hline Personal Factors & - Self-efficacy & $\begin{array}{ll}\text { - } & \text { Confidence problem- } \\
& \text { solving } \\
\text { - } & \text { Self-confidence } \\
\text { - } & \text { Empowerment } \\
\text { - } & \text { Self-advocacy }\end{array}$ \\
\hline $\begin{array}{l}\text { Environmental Factors } \\
\text { - Support and } \\
\text { relationships }\end{array}$ & $\begin{array}{l}\text { - Family } \\
\text { functioning }\end{array}$ & $\begin{array}{l}\text { - Family stress } \\
\text { - Family financial burden } \\
\text { - Impact of parent } \\
\text { employment } \\
\text { - Impact on all family } \\
\text { members } \\
\text { - Changing parental roles } \\
\text { - Family focus on pain } \\
\text { - Parent acceptance of } \\
\text { condition }\end{array}$ \\
\hline
\end{tabular}

Table 4. Content analysis codes and themes and ICF-CY linkage results 